\title{
Construction of a Stable Lanthanide Metal-Organic Framework as a Luminescent Probe for Rapid Naked-Eye Recognition of $\mathrm{Fe}^{3+}$ and Acetone
}

\author{
Jiayishuo Wang ${ }^{1,2}$, Muxin $\mathrm{Yu}^{1,3}{ }^{1}$, Lian Chen ${ }^{1, *} \mathbb{C}$, Zhijia $\mathrm{Li}^{1,2}$, Shengchang $\mathrm{Li}^{1,2}$, Feilong Jiang ${ }^{1}$ \\ and Maochun Hong ${ }^{1, *}$ \\ 1 Key Laboratory of Optoelectronic Materials Chemistry and Physics, Fujian Institute of Research on the \\ Structure of Matter, Chinese Academy of Sciences, Fuzhou 350002, China; wangjiayishuo@fjirsm.ac.cn (J.W.); \\ muxinyu@fjirsm.ac.cn (M.Y.); lizhijia@fjirsm.ac.cn (Z.L.); lishengchang@fjirsm.ac.cn (S.L.); \\ fjiang@fjirsm.ac.cn (F.J.) \\ 2 University of the Chinese Academy of Sciences, Beijing 100049, China \\ 3 Organic Optoelectronics Engineering Research Centre of Fujian's Universities, College of Electronics and \\ Information Science, Fujian Jiangxia University, Fuzhou 350108, China \\ * Correspondence: cl@fjirsm.ac.cn (L.C.); hmc@fjirsm.ac.cn (M.H.)
}

check for updates

Citation: Wang, J.; Yu, M.; Chen, L.; Li, Z.; Li, S.; Jiang, F.; Hong, M. Construction of a Stable Lanthanide Metal-Organic Framework as a Luminescent Probe for Rapid Naked-Eye Recognition of $\mathrm{Fe}^{3+}$ and Acetone. Molecules 2021, 26, 1695. https://doi.org/10.3390/ molecules26061695

Academic Editor: Mei Pan

Received: 9 February 2021

Accepted: 15 March 2021

Published: 18 March 2021

Publisher's Note: MDPI stays neutral with regard to jurisdictional claims in published maps and institutional affiliations.

Copyright: (C) 2021 by the authors. Licensee MDPI, Basel, Switzerland. This article is an open access article distributed under the terms and conditions of the Creative Commons Attribution (CC BY) license (https:/ / creativecommons.org/licenses/by/ $4.0 /)$.

\begin{abstract}
Four lanthanide metal-organic frameworks (Ln-MOFs), namely $\left\{\left[\mathrm{Me}_{2} \mathrm{NH}_{2}\right][\mathrm{LnL}] \cdot 2 \mathrm{H}_{2} \mathrm{O}\right\}_{\mathrm{n}}$ $(\mathrm{Ln}=\mathrm{Eu} 1, \mathrm{~Tb} 2$, Dy 3, Gd 4), have been constructed from a new tetradentate ligand 1-(3,5dicarboxylatobenzyl)-3,5-pyrazole dicarboxylic acid $\left(\mathrm{H}_{4} \mathrm{~L}\right)$. These isostructural Ln-MOFs, crystallizing in the monoclinic $P 2_{1}$ /c space group, feature a 3D structure with $7.5 \AA \times 9.8 \AA$ channels along the $b$ axis and the point symbol of $\left\{4^{10} \cdot 6^{14} \cdot 8^{4}\right\}\left\{4^{5} \cdot 6\right\}_{2}$. The framework shows high air and hydrolytic stability, which can keep stable after exposed to humid air for 30 days or immersed in water for seven days. Four MOFs with different lanthanide ions $\left(\mathrm{Eu}^{3+}, \mathrm{Tb}^{3+}, \mathrm{Dy}^{3+}\right.$, and $\left.\mathrm{Gd}^{3+}\right)$ ions exhibit red, green, yellow, and blue emissions, respectively. The Tb-MOF emitting bright green luminescence can selectively and rapidly $(<40 \mathrm{~s})$ detect $\mathrm{Fe}^{3+}$ in aqueous media via a fluorescence quenching effect. The detection shows excellent anti-inference ability toward many other cations and can be easily recognized by naked eyes. In addition, it can also be utilized as a rapid fluorescent sensor to detect acetone solvent as well as acetone vapor. Similar results of sensing experiments were observed from Eu-MOF. The sensing mechanism are further discussed.
\end{abstract}

Keywords: metal-organic frameworks; lanthanides; luminescence; $\mathrm{Fe}^{3+}$ sensors; acetone sensors

\section{Introduction}

Environmental and ecological problems have caused widespread concern of scientists in recent years. As an essential metal element in human metabolisms, $\mathrm{Fe}^{3+}$ ion plays a crucial role in muscle function, brain function, and hemoglobin [1,2]. Serious problems can be caused by the overloading or deficiency in the $\mathrm{Fe}^{3+}$ ion, such as immunosuppression, cognitive decline, and iron deficient anemia [3]. Likewise, acetone $\left(\mathrm{CH}_{3} \mathrm{COCH}_{3}\right)$, which is one of the critical members of volatile organic solvents (VOCs), has experienced an ever-growing attention not only in the laboratory and industry but also in the household, since it can cause irreversible damage to the human body, such as inhibiting breathing and causing dyspnea [4]. Accordingly, rapid and convenient detection of $\mathrm{Fe}^{3+}$ and acetone are increasingly essential for the environmental and ecological system.

In the recent decades, metal-organic frameworks (MOFs) have drawn increasing research interest on account of their unique features in their structures, such as permanent porosity, tunable structures, functions, and so on [5-8]. The potential applications of MOFs include but not limit to catalysis [9-11], sensing [12-20], optics [21-25], gas storage and separation [26-29], bio-imaging, and drug delivery [30-33]. In particular, lanthanide metalorganic frameworks (Ln-MOFs), displaying bright luminescence with large Stokes shifts, 
high quantum yields, and long lifetimes, are widely used as versatile materials in optics and sensing [34]. The forerunners have made great efforts on the recognition of environmentally and biologically relative species based on luminescent Ln-MOFs $[35,36]$. However, most of the MOFs reported for luminescent sensing are applied in nonaqueous media because of their poor hydrolytic stabilities [37]. In addition, the reports of rapid detection are few. The poor stabilities of the structures and the time consumption in the detection limit the further applications of MOFs in luminescent sensing. In light of these facts, we attempt to construct multifunctional Ln-MOFs for sensing in aqueous media conveniently and rapidly. Herein, a tetracarboxylic acid ligand, 1-(3,5-dicarboxylatobenzyl)-3,5-pyrazole dicarboxylic acid $\left(\mathrm{H}_{4} \mathrm{~L}\right.$, Scheme 1$)$, which can provide versatile coordination modes and Lewis base sites, was employed to construct four novel MOFs $\left\{\left[\mathrm{Me}_{2} \mathrm{NH}_{2}\right][\mathrm{LnL}] \cdot 2 \mathrm{H}_{2} \mathrm{O}\right\}_{n}(\mathrm{Ln}=\mathrm{Eu} 1, \mathrm{~Tb} 2, \mathrm{Dy}$ 3 , and Gd 4). The MOFs demonstrate excellent air and water stabilities as well as colorful luminescence. Based on these virtues, a convenient and fast-response luminescent sensor toward the $\mathrm{Fe}^{3+}$ ion in aqueous solution with good anti-inference ability was fabricated. It also shows the potential for quickly sensing acetone solvent as well as its vapor in the air. The simplicity, visualization, and high time efficiency of this method make it a competitive dual-functional fluorescent probe.

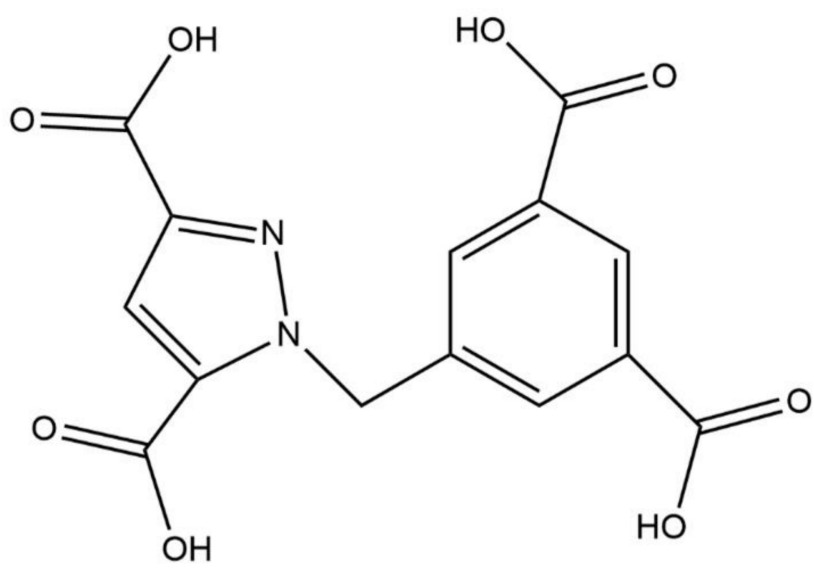

Scheme 1. 1-(3,5-dicarboxylatobenzyl)-3,5-pyrazole dicarboxylic acid $\left(\mathrm{H}_{4} \mathrm{~L}\right)$.

\section{Results and Discussion}

2.1. Structure Description of $\left\{\left[\mathrm{Me}_{2} \mathrm{NH}_{2}\right][\mathrm{LnL}] \cdot 2 \mathrm{H}_{2} \mathrm{O}\right\}_{n}(\mathrm{Ln}=\mathrm{Eu} \mathbf{1}, \mathrm{Tb} \mathbf{2}, \mathrm{Dy} \mathbf{3}, \mathrm{Gd}$ 4) (Compounds 1-4)

Crystal data and refinement results for compounds 1-4 are listed in Table 1.

Single crystal X-ray diffraction analysis (SCXRD) shows that the four compounds are isomorphic. Therefore, we choose 4 (Gd-MOF) as a representative to elaborate the structure. Crystal structure analysis reveals that it crystallizes in space group $\mathrm{P} 2{ }_{1} / \mathrm{c}$. The asymmetric unit contains a crystallographically-independent $\mathrm{Gd}^{3+}$ ion, a fully deprotonated $[\mathrm{L}]^{4-}$ ligand, and an isolated dimethylamine cation (Figure S2). In the compound, the coordination environment of the nine-coordinated gadolinium center is composed of six oxygen atoms from three chelating bidentate carboxylate groups and three oxygen atoms from three $\mu_{2}$-bridging carboxylate groups (Figure 1a). The Gd1 atom and its corresponding symmetrically generated one are bridged by four bidentate carboxylic groups of four [L] ${ }^{4-}$ ligands to form a binuclear metal cluster unit $\left[\mathrm{Gd}_{2}(\mathrm{COO})_{4}\right]$ (Figure $1 \mathrm{~b}$ ). The coordination mode of the ligand is a $\mu_{6}$-bridging mode connecting with six $\mathrm{Gd}^{3+}$ ions from four $\left[\mathrm{Gd}_{2}(\mathrm{COO})_{4}\right]$ clusters, where two carboxylate groups adopt a chelating bidentate mode and the other two carboxylate groups adopt a $\mu_{2}$-bridging bidentate mode, respectively (Figure $1 \mathrm{c}$ and Figure $\mathrm{S} 3$ ). Each $\left[\mathrm{Gd}_{2}(\mathrm{COO})_{4}\right]$ cluster is connected with the other 14 binuclear clusters through eight $[\mathrm{L}]^{4-}$ ligands (Figure 1d). As shown in Figure 1e, the binuclear metal cluster units are further interconnected to form an infinite 3D framework through 
the organic linkers, showing a 1D open channel along the b-axis with the approximate size of $7.5 \AA \times 9.8 \AA$.

Table 1. Crystal data and refinement results for compounds 1-4.

\begin{tabular}{|c|c|c|c|c|}
\hline Compound & 1 & 2 & 3 & 4 \\
\hline Empirical formula & $\mathrm{C}_{16} \mathrm{H}_{14} \mathrm{EuN}_{3} \mathrm{O}_{8}$ & $\mathrm{C}_{16} \mathrm{H}_{14} \mathrm{TbN}_{3} \mathrm{O}_{8}$ & $\mathrm{C}_{16} \mathrm{H}_{14} \mathrm{DyN}_{3} \mathrm{O}_{8}$ & $\mathrm{C}_{16} \mathrm{H}_{14} \mathrm{GdN}_{3} \mathrm{O}_{8}$ \\
\hline Formula weight & 528.27 & 535.23 & 538.80 & 533.55 \\
\hline Crystal system & monoclinic & monoclinic & monoclinic & monoclinic \\
\hline Space group & $P 2_{1} / c$ & $P 2_{1} / c$ & $P 2_{1} / c$ & $P 2_{1} / c$ \\
\hline$a / \AA$ & $9.1791(2)$ & $9.2477(2)$ & $9.1815(5)$ & $9.2303(5)$ \\
\hline$b / \AA$ & $10.1636(3)$ & $10.1192(2)$ & $10.1647(4)$ & $10.1530(4)$ \\
\hline$c / \AA$ & $21.7390(5)$ & $21.7150(5)$ & $21.7438(9)$ & $21.8214(9)$ \\
\hline$\alpha /^{\circ}$ & 90 & 90 & 90 & 90 \\
\hline$\beta /^{\circ}$ & $99.829(2)$ & $100.542(2)$ & $99.809(4)$ & $100.353(4)$ \\
\hline$\gamma /{ }^{\circ}$ & 90 & 90 & 90 & 90 \\
\hline Volume $/ \AA^{3}$ & 1998.32(9) & 1997.78(8) & 1999.62(16) & 2011.70(16) \\
\hline Z & 4 & 4 & 4 & 4 \\
\hline$F(000)$ & 924 & 909 & 936 & 1076 \\
\hline Goodness-of-fit on $F^{2}$ & 1.082 & 1.021 & 1.07 & 1.03 \\
\hline$R_{1}(\mathrm{I}>2 \sigma(\mathrm{I}))$ & 0.0311 & 0.0282 & 0.0387 & 0.0259 \\
\hline$w R_{2}$ (reflections) & 0.0848 & 0.0587 & 0.0701 & 0.1056 \\
\hline
\end{tabular}

$a, b$ and $c$ are the unit vectors of unit cell. $\alpha, \beta$, and $\gamma$ are the unit cell parameters (angles between $a, b$ and $c$ ). $Z$ is the number of molecules in unit cell. F (000) is the total number of electrons in unit cell. $R_{1}$ is residual factors. I is diffraction intensity. $\sigma$ is standard deviation. $w R_{2}$ is residual factors.

(a)

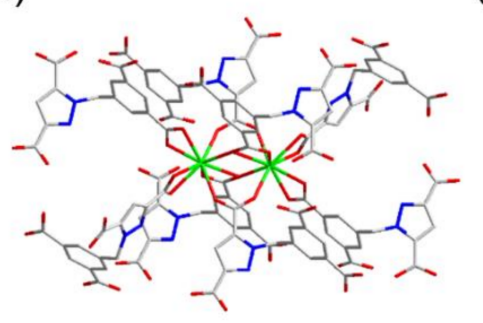

(d)

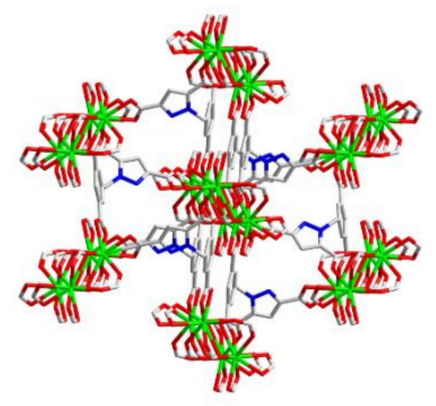

(b)

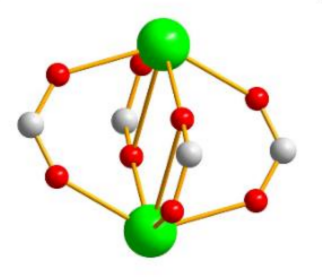

(c)

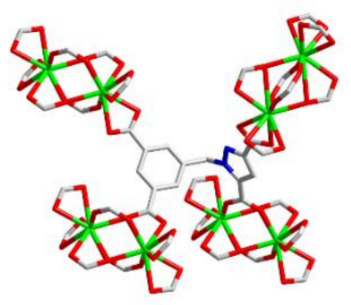

(e)

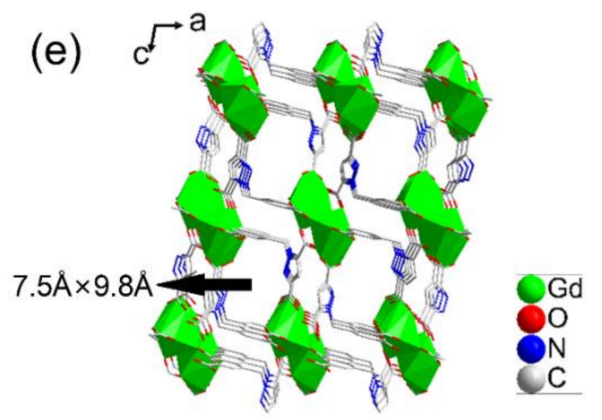

Figure 1. (a) Coordination environment of the $\mathrm{Gd}^{3+}$ ion in Gd-metal-organic frameworks (MOF) $\left(\mathrm{Gd}\right.$, green, $\mathrm{O}$, red, $\mathrm{N}$, blue, $\mathrm{C}$, gray). (b) The binuclear metal cluster unit $\left[\mathrm{Gd}_{2}(\mathrm{COO})_{4}\right]$. (c) The coordination mode of the $[\mathrm{L}]^{4-}$ ligand. (d) The coordination mode of the binuclear metal cluster unit $\left[\mathrm{Gd}_{2}(\mathrm{COO})_{4}\right]$. (e) The 3D framework viewed along the b-axis.

Topological analysis [38] shows that the structure can be simplified as a new $(4,8)$ connected net with stoichiometry $(4-c)(8-c)_{2}$ and point symbol of $\left\{4^{10} .6^{14} .8^{4}\right\}\left\{4^{5} .6\right\}_{2}$ when the binuclear metal cluster units and ligands are considered as eight-connected nodes and four-connected linkers, respectively (Figure 2). Powder X-ray diffraction (PXRD) patterns were then recorded to analyze the phase purity of the obtained compounds. The results reveal that the samples of four MOFs are of high purity (Figure S4). 
(a)
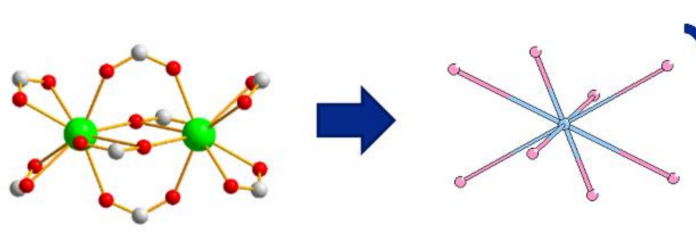

(c)

(b)
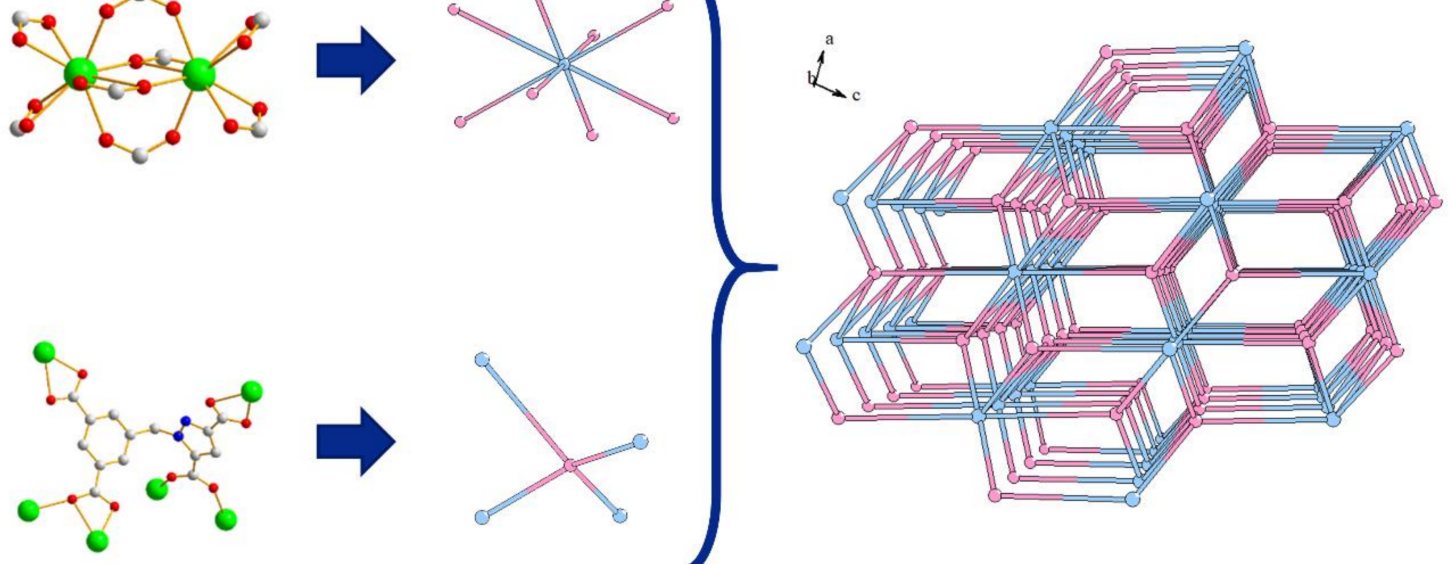

Figure 2. (a) The simplified eight-connected node of the binuclear unit. (b) The simplified 4-connected linker. (c) The (4, 8)-connected topological 3D net with the Schläfli symbol $\left\{4^{10} .6^{14} .8^{4}\right\}\left\{4^{5} .6\right\}_{2}$.

\subsection{Framework Stability}

The framework stability of MOFs is of vital importance for their practical applications. Therefore, the following experiments were carried out. First, thermogravimetry analyses (TGA) for the four compounds were studied (Figure S5). The results show that the thermogravimetric curves of the four samples overlap together. When the temperature rises to $180{ }^{\circ} \mathrm{C}$, the weight loss is about $6.3 \%$, which should be the escape of two water molecules. The frameworks keep stable up to $288^{\circ} \mathrm{C}$ and begin to collapse when the temperature exceeds $288^{\circ} \mathrm{C}$. Since the MOFs have the same frameworks, $\mathbf{2}$ is selected for the further tests. A thermo-diffractogram obtained from $30{ }^{\circ} \mathrm{C}$ to $450{ }^{\circ} \mathrm{C}$ demonstrates the crystalline structure keeps stable from $30-200{ }^{\circ} \mathrm{C}$, slightly changes at $300{ }^{\circ} \mathrm{C}$, and finally collapses when the temperature comes up to $400{ }^{\circ} \mathrm{C}$ (Figure S6a). The observation is in accordance with the result from TGA. The air stability is determined by collecting PXRD patterns after a period of exposure in the atmosphere with a humidity of ca. 55\%. The unchanged PXRD patterns reveal that the framework can survive in the humid air for more than 30 days (Figure S6b). The PXRD patterns of the samples immersed in water shows that the water stability of the framework is excellent (remain stable for more than 7 days (Figure S6c)). Chemical stability of the MOF was also evaluated. The samples were immersed in aqueous solutions with the $\mathrm{pH}$ values varying from 2 to 11 for $42 \mathrm{~h}$. Then, the filtered samples were dried in air. The nearly unchanged PXRD patterns with $\mathrm{pH}$ values from 5 to 10 indicate relatively good chemical stability (Figure S6d).

\subsection{Luminescent Properties}

The luminescence properties of the ligand and compounds 1-4 in a solid state are shown in Figure 3 and Figure S7. $\mathrm{Ln}^{3+}$ ions suffer from weak light absorption with the absorption coefficients generally less than $10 \mathrm{M}^{-1} \mathrm{~cm}^{-1}$ due to the "Laporte forbidden" feature of the transitions between the $4 \mathrm{f}^{\mathrm{n}}$ configurations of the $\mathrm{Ln}^{3+}$ Ions. According to the famous "antenna effect" theory founded by Weissman in 1942 [39-41], the organic ligand can efficiently absorb light and transfer this energy to the excited states of the central lanthanide ions by overcoming the weak absorption of lanthanide and, thus, leading to the improvement of the emission efficiency. When excited at $297 \mathrm{~nm}, \mathbf{1}$ shows the characteristic red emission with the emissions at $580 \mathrm{~nm}, 591 \mathrm{~nm}, 613 \mathrm{~nm}, 615 \mathrm{~nm}$, and $700 \mathrm{~nm}$ corresponding to ${ }^{5} \mathrm{D}_{0} \rightarrow{ }^{7} \mathrm{~F}_{\mathrm{J}}(\mathrm{J}=1-4)$ transitions of Eu ${ }^{3+}$ centers, respectively (Figure 3a). Under the excitation of $299 \mathrm{~nm}, 2$ exhibits characteristic green emission with the peaks at $488 \mathrm{~nm}, 619 \mathrm{~nm}, 543 \mathrm{~nm}, 584 \mathrm{~nm}$, and $619 \mathrm{~nm}$, ascribed to ${ }^{5} \mathrm{D}_{4} \rightarrow{ }^{7} \mathrm{~F}_{\mathrm{J}}(\mathrm{J}=6,5$, 4 , and 3) transitions of $\mathrm{Tb}^{3+}$ ions (Figure $3 \mathrm{~b}$ ). 3 displays yellow emission bands at $479 \mathrm{~nm}$, $573 \mathrm{~nm}, 663 \mathrm{~nm}$, and $751 \mathrm{~nm}$ upon excitation at $287 \mathrm{~nm}$, which are due to ${ }^{7} \mathrm{~F}_{9 / 2} \rightarrow{ }^{6} \mathrm{H}_{\mathrm{J}}$ 
$(\mathrm{J}=12 / 2,13 / 2,11 / 2,7 / 2)$ transitions of $\mathrm{Dy}^{3+}$ ions (Figure 3c). Similar bands around $300 \mathrm{~nm}$ observed in the excitation spectra (dash lines, Figure 3 ) of the three complexes may be ascribed to the $n \rightarrow \pi^{*}$ or $\pi \rightarrow \pi^{*}$ transitions of the ligand. The ligand displays a broad band at 370-550 $\mathrm{nm}$ on the excitation of $346 \mathrm{~nm}$ (Figure S7a). Apart from $\mathrm{Eu}^{3+}$, $\mathrm{Tb}^{3+}$, and $\mathrm{Dy}^{3+}$ ions, the energy levels of $\mathrm{Gd}^{3+}$ ion are too high so that the energy from the lowest triplet state energy level (T1) of the ligand cannot be transferred to the $\mathrm{Gd}^{3+}$ center, bringing about the broad blue emission similar to that of the pure ligand (Figure S7b). The phosphorescence spectrum of 4 at $77 \mathrm{~K}$ reveals that the triplet state energy level $\mathrm{T}_{1}$ of the ligand is $24,570 \mathrm{~cm}^{-1}(407 \mathrm{~nm})$. The Commission Internationale de l'Éclairage (CIE) 1931 chromaticity diagram shows the different emission colors of the compounds (Figure 3d). The room temperature quantum yields and lifetimes of compounds $\mathbf{1}, \mathbf{2}$, and $\mathbf{3}$ were also measured and shown in Table S1 and Figure S8. Compared with the low quantum yield of 3 , those of $\mathbf{1}$ and $\mathbf{2}$ are as high as $39.29 \%$ and $57.77 \%$, respectively, indicating that $\mathrm{Eu}^{3+}$ and $\mathrm{Tb}^{3+}$ can be better sensitized by the ligand when compared with $\mathrm{Dy}^{3+}$. This can be further proven by the larger lifetimes of compounds $\mathbf{1}$ and $\mathbf{2}$.

(a)

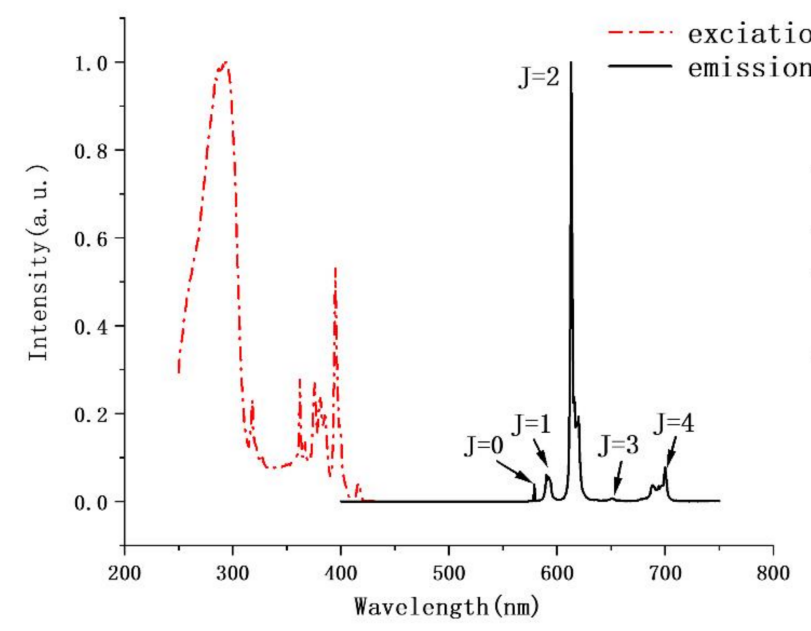

(c)

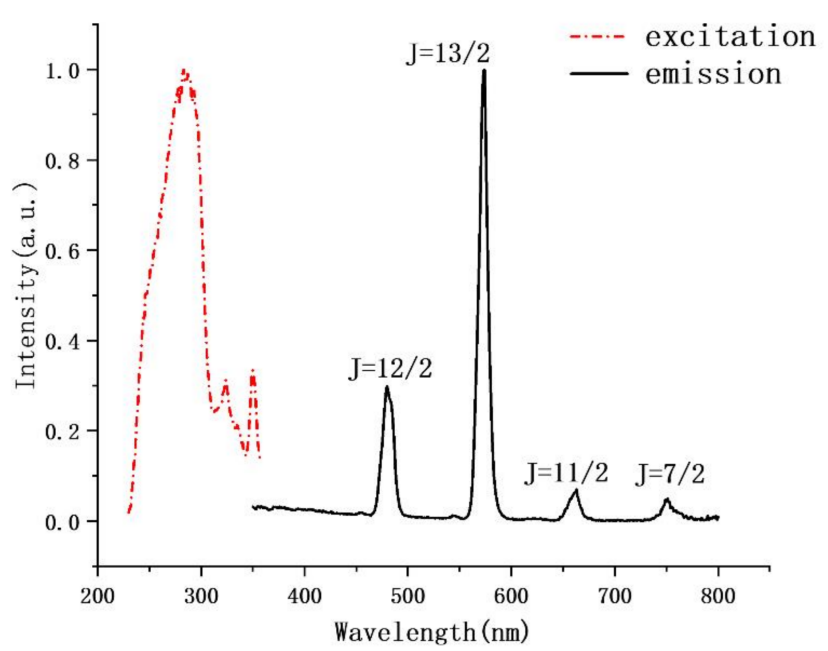

(b)

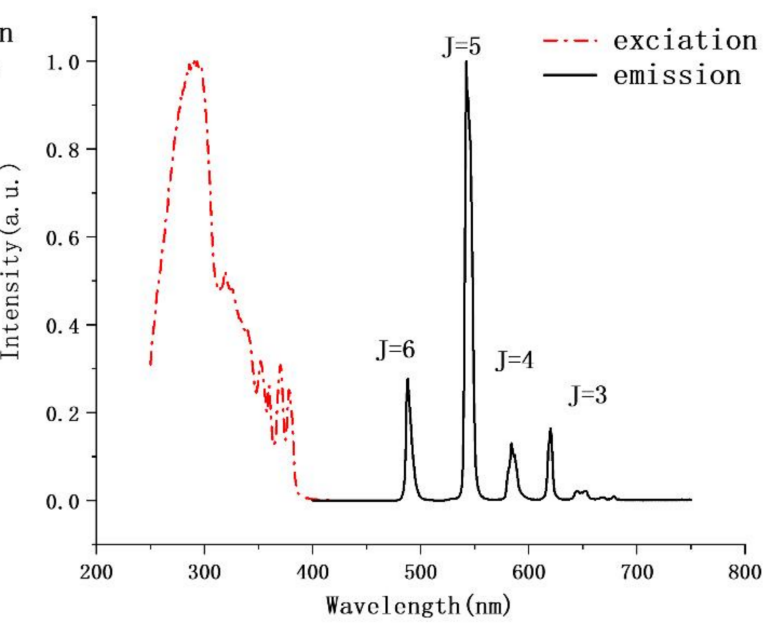

(d)

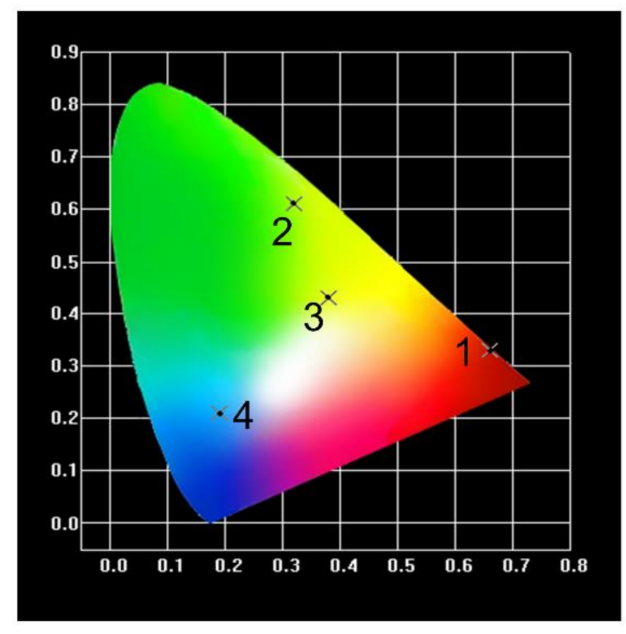

Figure 3. (a) The excitation $\left(\lambda_{\mathrm{em}}=614 \mathrm{~nm}\right)$ and emission spectra $\left(\lambda_{\mathrm{ex}}=297 \mathrm{~nm}\right)$ of 1 . (b) The excitation $\left(\lambda_{\mathrm{em}}=543 \mathrm{~nm}\right)$ and emission spectra $\left(\lambda_{\mathrm{ex}}=299 \mathrm{~nm}\right)$ of compound 2. (c) The excitation $\left(\lambda_{\mathrm{em}}=574 \mathrm{~nm}\right)$ and emission spectra $\left(\lambda_{\mathrm{ex}}=287 \mathrm{~nm}\right)$ of compound 3. (d) CIE-1931 chromaticity diagram shows the luminescence colors of compounds $1(0.66,0.33), 2(0.32,0.61), 3$ $(0.38,0.43)$, and $4(0.19,0.21)$. 


\subsection{Sensing of Cations}

Porous characteristics, excellent hydrolytic stability, and intensive luminescence presented above inspire us to explore the potential of the Ln-MOFs for chemical sensing in aqueous media. 2 was selected for cation detection in consideration of its highest luminescent efficiency in four compounds. Then, $3 \mathrm{mg}$ of 2 was dispersed into $3 \mathrm{~mL}$ of water, and the fluorescence intensity of the suspension was measured as the blank sample. Then $\mathbf{2}$ was dispersed into aqueous solution of $1 \mathrm{mMM}\left(\mathrm{NO}_{3}\right)_{\mathrm{x}}$ of different kinds of metal ions $\left(\mathrm{M}^{2} \mathrm{Li}^{+}\right.$, $\mathrm{Ni}^{2+}, \mathrm{Mg}^{2+}, \mathrm{In}^{3+}, \mathrm{K}^{+}, \mathrm{Al}^{3+}, \mathrm{Zn}^{2+}, \mathrm{Ca}^{2+}, \mathrm{Cu}^{2+}$, or Fe ${ }^{3+}$ ). The fluorescence spectra of suspensions show that the intensity of $543 \mathrm{~nm}$ has slight or negligible changes in the presence of most ions except the $\mathrm{Fe}^{3+}$ cation (Figure 4a and Figure S9). A remarkable quenching occurs in the $\mathrm{Fe}^{3+}$ ion solution, which can be easily observed under the irradiation of ultraviolet (UV) light with naked eyes. This indicates that 2 can be used to selectively detect the $\mathrm{Fe}^{3+}$ ion in aqueous solution.

(a)

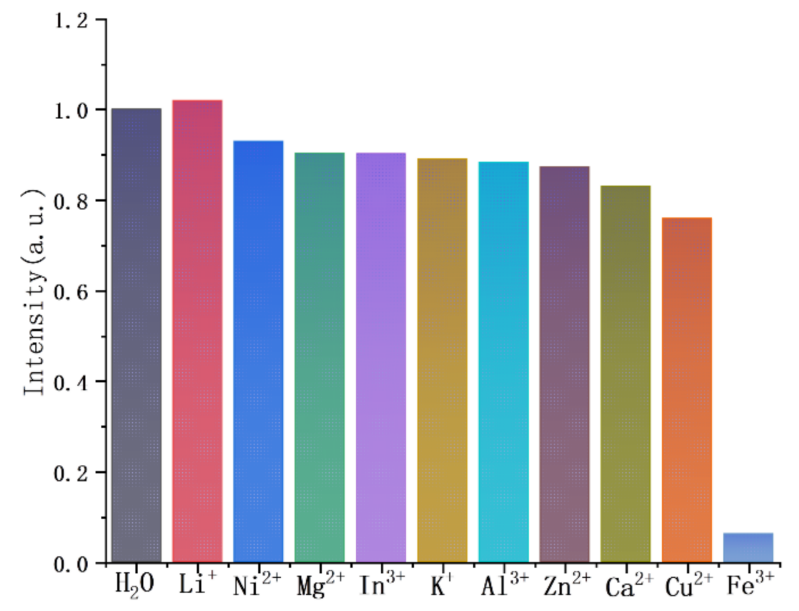

(b)

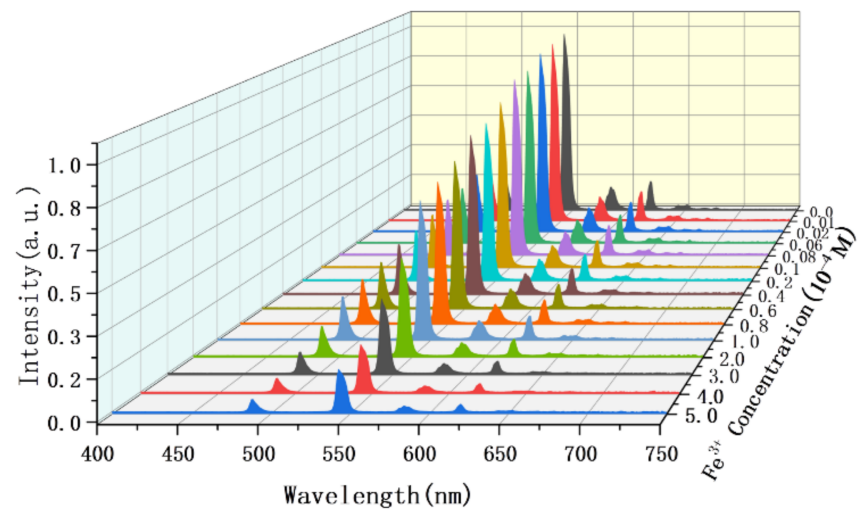

(d)

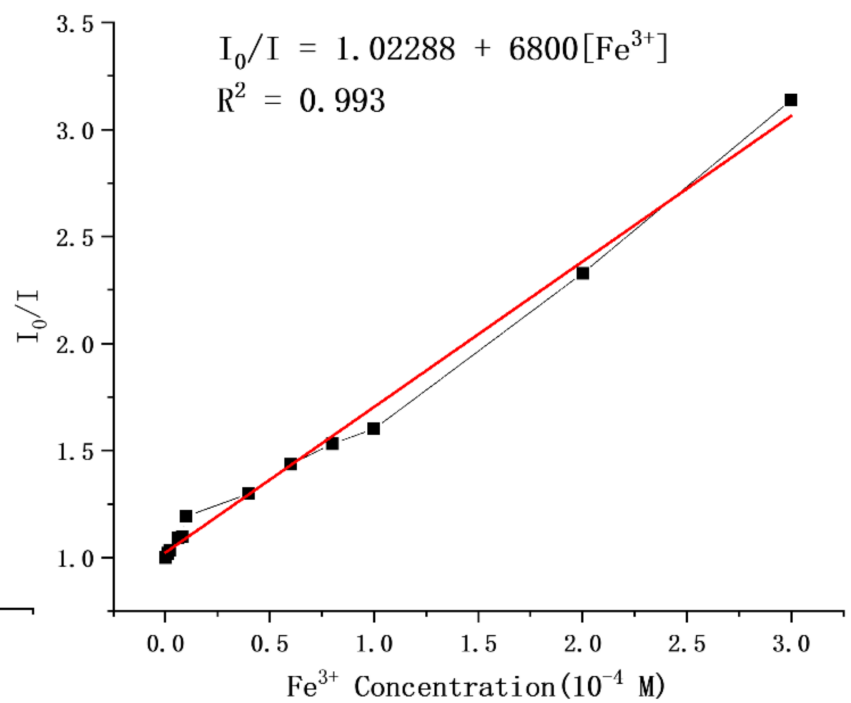

Figure 4. (a) Comparison of the ${ }^{5} \mathrm{D}_{4} \rightarrow{ }^{7} \mathrm{~F}_{5}$ photoluminescence intensity of 2 in water and aqueous solutions containing different metal ions when excited at $299 \mathrm{~nm}$. (b) Photoluminescence spectra, (c) quenching efficiency, and (d) a Stern-Volmer plot of 2 with a gradual increase of the $\mathrm{Fe}^{3+}$ concentration in aqueous solution. 
The concentration-dependent luminescence of $\mathrm{Fe}^{3+}$ was studied in the presence of $\mathrm{Fe}^{3+}$ from 0 to $5 \times 10^{-4} \mathrm{M}$ (Figure $4 \mathrm{~b}$ ). The quenching effect can be clearly observed at the concentration of $6 \times 10^{-6} \mathrm{M}$ (Figure $4 \mathrm{c}, \mathrm{d}$ ). The fluorescence quenching efficiency is measured by using the formula: $\left.\left(1-\mathrm{I} / \mathrm{I}_{0}\right) \times 100 \%\right)$, suggesting that 2 shows a high sensitivity in fluorescence quenching sensing. The quenching effect coefficient $\left(K_{\mathrm{sv}}\right)$, which verifies the quenching effect, is calculated according to the Stern-Volmer (SV) equation: $\mathrm{I}_{0} / \mathrm{I}=1+K_{\mathrm{sv}}[\mathrm{M}]$, where $\mathrm{I}_{0}$ and $\mathrm{I}$ represent the luminescent intensities before and after analyte addition, respectively. $[\mathrm{M}]$ represents the molar concentration of metal ions. In the concentration from 0 to $3 \times 10^{-4} \mathrm{M}$, the Stern-Volmer quenching curve is close to the first-order linearity, with the correlation coefficient of linear fitting 0.993 , and the fitted linear equation $\mathrm{I}_{0} / \mathrm{I}=1.02288+6800\left[\mathrm{Fe}^{3+}\right]$. However, there is no linear correlation but only an upward curve when the concentration reaches up to $3 \times 10^{-4} \mathrm{M}$. The non-linear nature suggests the mechanism of the quenching can be attributed to the combination of dynamic and static quenching [42,43].

During the experiment, it was found that the fluorescence of the sample can be quenched by $\mathrm{Fe}^{3+}$ ions in a remarkably short contact time, so we studied the relationship between the $\mathrm{Fe}^{3+}$ contact time and the fluorescence intensity. The result showed that the maximum quenching efficiency is achieved in $40 \mathrm{~s}$, and then it remains unchanged (Figure 5a and Figure S10). The phenomenon indicates that the $\mathbf{2}$ has an ultrafast fluorescence response to the $\mathrm{Fe}^{3+}$ ion, which is expected to be applied to real-time sensing.

(a)

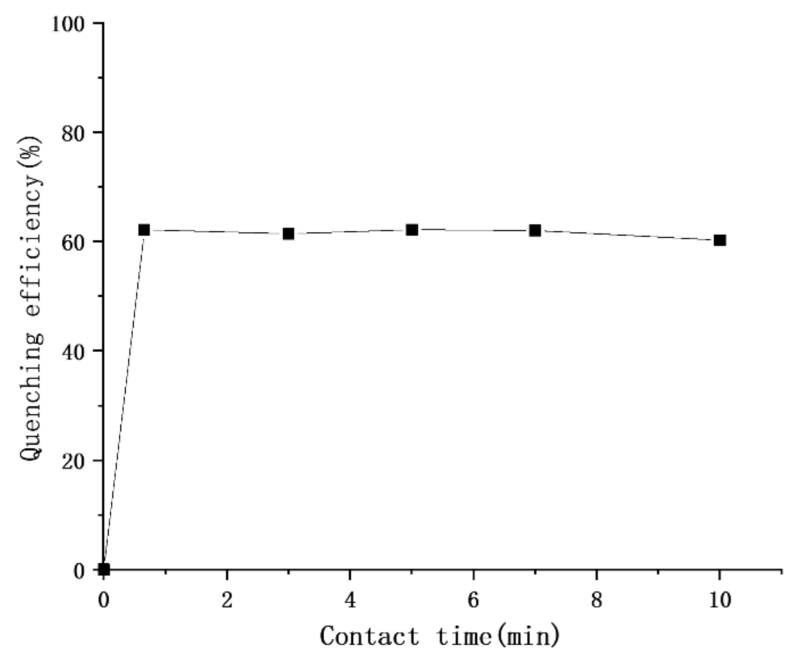

(b)

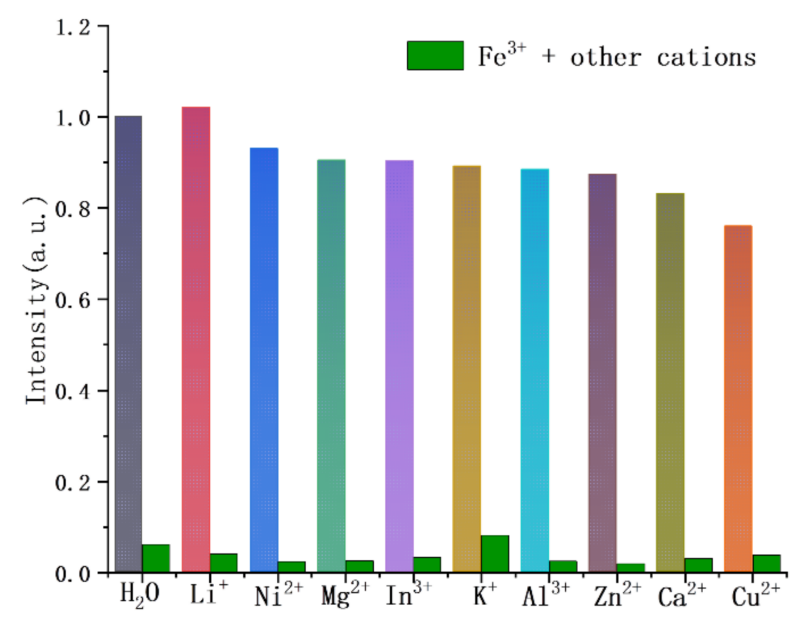

(c)

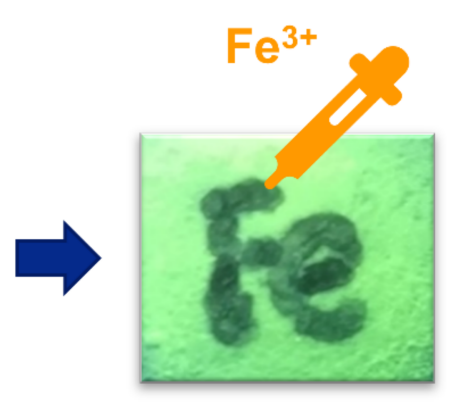

Figure 5. (a) Time-dependent quenching efficiency of 2 in the presence of $\mathrm{Fe}^{3+}$ solutions $\left(3 \times 10^{-4} \mathrm{M}\right)$. (b) Comparison of the ${ }^{5} \mathrm{D}_{4} \rightarrow{ }^{7} \mathrm{~F}_{5}$ photoluminescence intensity of compound 2 in the pure individual metal ions and mixed metal ions containing $1 \mathrm{mM}$ of $\mathrm{Fe}^{3+}$ ion. (c) The image of 2 paper-coated sensor treated with $0.01 \mathrm{M} \mathrm{Fe}^{3+}$ solution.

In order to study the anti-interference ability toward other cations, sensing experiments were carried out in aqueous solution with a mixture of $\mathrm{Fe}^{3+}$ ion and other metal 
cations. The emission intensity of 2 in aqueous solution of mixed cations $\left(\mathrm{Li}^{+}, \mathrm{Ni}^{2+}, \mathrm{Mg}^{2+}\right.$, $\mathrm{In}^{3+}, \mathrm{K}^{+}, \mathrm{Al}^{3+}, \mathrm{Zn}^{2+}, \mathrm{Ca}^{2+}$ and $\mathrm{Cu}^{2+}, 1 \times 10^{-3} \mathrm{M}$ each) shows only a slight quenching compared with the intensity in pure water (Figure S11). Once the $\mathrm{Fe}^{3+}$ ion $\left(1 \times 10^{-3} \mathrm{M}\right)$ was added, the slightly changed fluorescence intensity of $\mathbf{2}$ in other cationic solutions immediately shows a dramatic decrease (Figure $5 b$ ). It indicates that the presence of interference ions has little influence on fluorescence detection of $\mathbf{2}$ toward the $\mathrm{Fe}^{3+}$ ion.

Furthermore, a fluorescent test paper was made to realize a simple, portable, and realtime $\mathrm{Fe}^{3+}$ ion sensor. The capillary dipped in $0.01 \mathrm{M} \mathrm{Fe}^{3+}$ ion aqueous solution was used to write "Fe" on the fluorescent test paper. The position with writing marks was quenched immediately under the irradiation of a UV lamp (Figure 5c). The above experimental results indicate that the 2 could be employed as a convenient, rapid, and easily-recognized probe for $\mathrm{Fe}^{3+}$ with good anti-interference ability.

\subsection{Sensing of Organic Molecules}

Volatile organic solvents (VOCs) are widely used in laboratory and industrial products. However, they have adverse impact on human health and the environment. As one of the most burgeoning fluorescent probe materials, MOFs are widely used in the detection of organic molecules. To explore the potential application of $\mathbf{2}$ as a fluorescent sensor for VOCs, a certain amount of its powder was ground and dispersed in different organic solvents, including $n$ - $\mathrm{BuOH}, \mathrm{EtOH}, \mathrm{MeOH}, N, N^{\prime}$-dimethylformamide (DMF), $i-\mathrm{PrOH}, \mathrm{CH}_{2} \mathrm{Cl}_{2}$, $\mathrm{C}_{4} \mathrm{H}_{10} \mathrm{O}, \mathrm{CH}_{3} \mathrm{CN}$, tetrahydrofuran (THF), benzene, toluene, $n$-pentane, and acetone. The photoluminescence test was carried out after ultrasonic dispersing the sample evenly. As shown in Figure 6a and Figure S12, the ${ }^{5} \mathrm{D}_{4} \rightarrow{ }^{7} \mathrm{~F}_{5}$ fluorescence intensity of 2 shows no significant change in most organic solvents while the intensity drops abruptly when $\mathbf{2}$ is dispersed in acetone. It suggests that $\mathbf{2}$ may be a selective sensor toward acetone solvent. Then, a concentration-dependent experiment was carried out. Different concentrations of acetone were dissolved in $3 \mathrm{~mL}$ of DMF and $3 \mathrm{mg}$ of 2 was then added. The quenching efficiency of the emulsion shows a gradual increase with the growing acetone concentration. A significant variation can be observed when the concentration of acetone is as low as 0.04 vol.\%. From 0.04 vol.\% to 0.2 vol.\%, the increasing trend of the luminescent quenching efficiency of 2 at $543 \mathrm{~nm}$ versus the volume ratio of acetone can be fitted with a first-order exponential decay. In addition, the quenching efficiency of $\mathbf{2}$ toward acetone comes up to $70 \%$ at 0.5 vol. $\%$ (Figure $6 \mathrm{~b}, \mathrm{c}$ ).

The response time of $\mathbf{2}$ to acetone in liquid was also tested. The result demonstrates that the response of 2 to $\mathrm{Fe}^{3+}$ ion has already finished in $40 \mathrm{~s}$ (Figure $6 \mathrm{~d}$ and Figure S13). The phenomenon indicates that the probe responds to acetone very quickly. The apparent brightness change, which can be observed with the naked-eye under the irradiation of the UV light, indicates that 2 can be used to detect acetone conveniently (Figure 6e).

Since acetone is an extremely volatile and highly toxic gas, the detection of acetone vapor is of vital importance. Despite some luminescent sensors for acetone solvent being reported, few efforts have been made for the exploration of the rapid detection of acetone vapor [44,45]. Upon exposure to saturated acetone vapor for $40 \mathrm{~s}$, the fluorescence intensity of solid sample 2 drastically decreases $69.2 \%$ (Figure $6 \mathrm{f}$ ). At $60 \mathrm{~s}$, the decrease comes to $87.8 \%$. Moreover, the decline of the intensity turns to $94.5 \%$ when 2 is exposed to acetone for $140 \mathrm{~s}$. These phenomena indicate that compound 2 can detect acetone vapor in an extremely short time.

\subsection{Sensing Mechanism}

The superb detection performance of the compounds prompts us to explore the possible mechanism of luminescence quenching caused by $\mathrm{Fe}^{3+}$ and acetone. First, the PXRD patterns of the samples after sensing experiments were recorded (Figures S14 and S15). The nearly unchanged patterns show the samples keep their crystalline structure after treatment, indicating that the luminescence quenching is not caused by the collapse of the framework. 
(a)

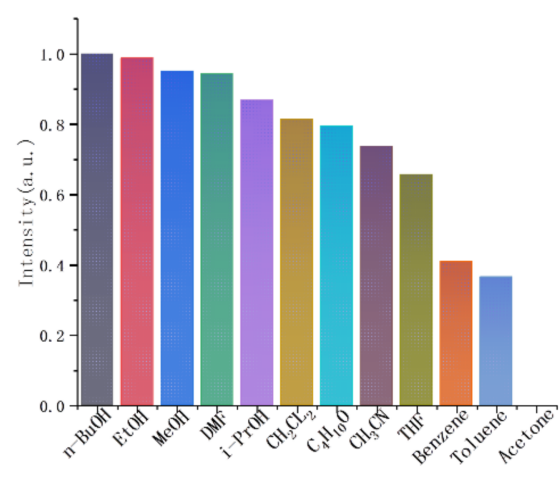

(d)

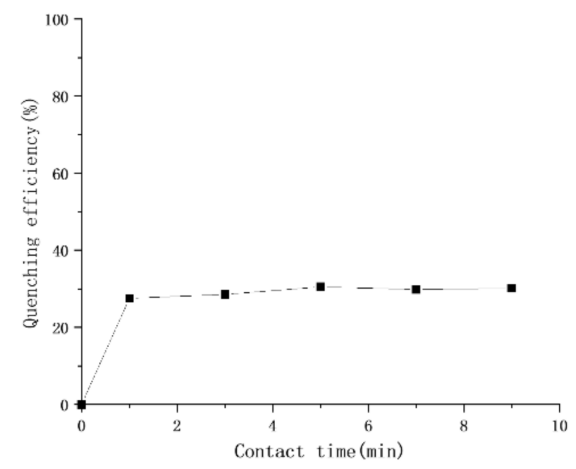

(b)

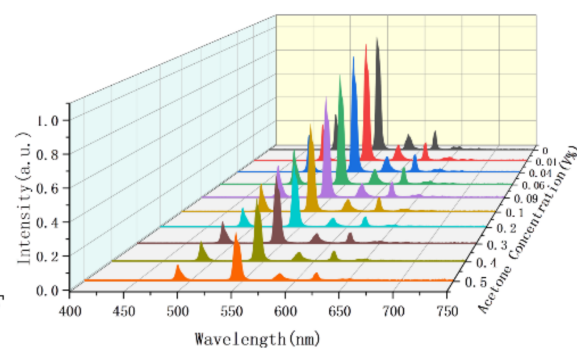

(c)

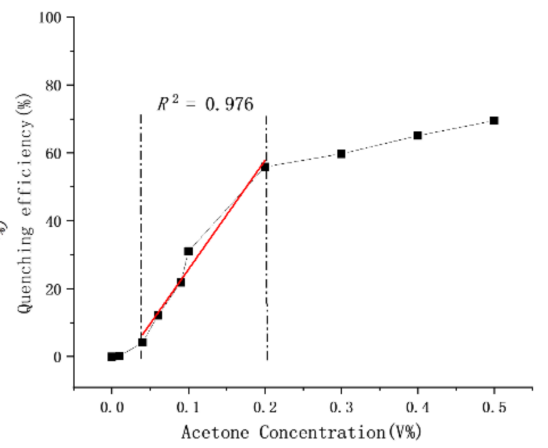

(f)

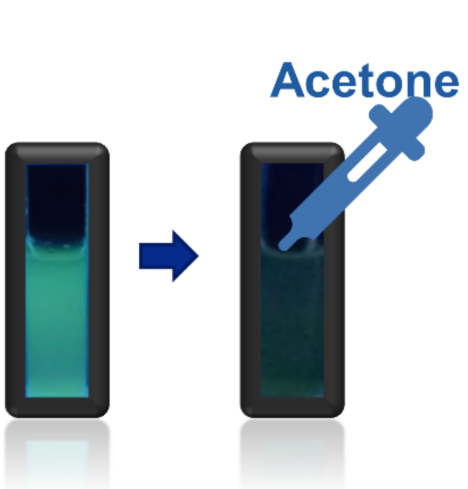

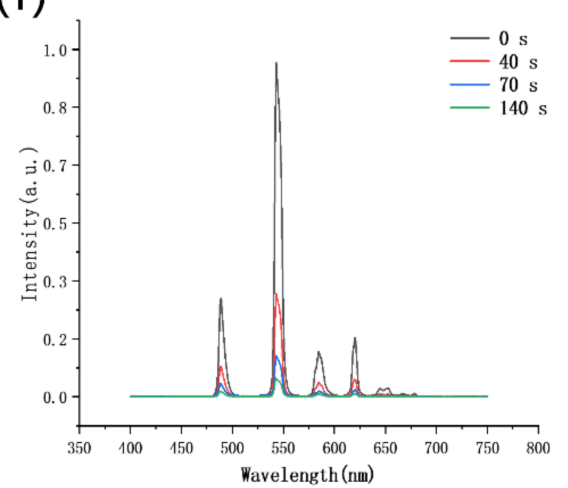

Figure 6. (a) Comparison of the ${ }^{5} \mathrm{D}_{4} \rightarrow{ }^{7} \mathrm{~F}_{5}$ photoluminescence intensity of $\mathbf{2}$ in different organic molecules when excited at $299 \mathrm{~nm}$. (b) Photoluminescence spectra and (c) quenching efficiency of 2 with a gradual increase in the concentration of acetone in $N, N^{\prime}$-dimethylformamide (DMF). (d) Time-dependent quenching efficiency of $\mathbf{2}$ suspension in the presence of acetone in DMF (0.1 vol.\%). (e) Photographs of 2 suspension before and after adding acetone. (f) Time-dependent solid photoluminescence spectra of solid-state 2 upon exposure to acetone vapor.

In light of previous studies, competitive energy absorption between analytes and Ln-MOFs may be a very possible reason for the luminescence quenching. With this in mind, the UV-vis spectra of the $\mathrm{Fe}^{3+}$ as well as other metal ions (measured in aqueous solution, $2 \times 10^{-4} \mathrm{M}$ ) and the acetone (measured in DMF solution, 0.2 vol.\%) were recorded. As shown in Figure S16, only the UV-vis absorption spectrum of $\mathrm{Fe}^{3+}$ has significant absorption around $295 \mathrm{~nm}$, which shows a clear overlap with the excitation spectrum of 2 (Figure 3b). This implies that there is competitive absorption of the light source energy between $\mathrm{Fe}^{3+}$ and 2, and, hence, leads to the quenching behavior. Similarly, spectral overlap is observed between the excitation spectrum of compound $\mathbf{2}$ and the UV-vis absorption spectrum of acetone ranging from $260 \mathrm{~nm}$ to $323 \mathrm{~nm}$ (Figure S17).

Based on the above results, we surmise that the main reason of fluorescence quenching can be attributed to the competitive energy absorption between analytes ( $\mathrm{Fe}^{3+}$ and acetone) and Ln-MOFs. However, we still wonder if there are any other possible mechanisms involved in the luminescence quenching. UV-vis adsorption spectra of $\mathrm{Fe}^{3+}$ aqueous solution with different concentrations were then recorded. As Figure S18 shows, there is almost no absorption near $300 \mathrm{~nm}$ when the concentration of $\mathrm{Fe}^{3+}$ ions is lowered to $6 \times 10^{-6} \mathrm{M}$, but still ca. $8.5 \%$ luminescence quenching occurs. This indicates that there may be another reason for the quenching. Furthermore, it is worth noting that 2 shows clear fluorescence quenching towards acetone vapor. In this sensing experiment, luminescence of solid samples instead of suspension was recorded. Thus, the influence caused by the absorption of acetone can be nearly neglected. These facts give us a clue that there may be another mechanism in the quenching process. 
To further investigate the other possible mechanism, the isomorphic $\mathbf{1}$ was chosen to implement the same sensing tests of metal ions and organic solvents. The outcomes of the experiments are consistent with those of 2 (Figures S19 and S20). The luminescence of Eu-MOF also shows selectivity responses towards $\mathrm{Fe}^{3+}$ and acetone. The results give a reasonable indication that the other sensing mechanism does not come from the $\mathrm{Tb}^{3+}$ ions, but may be associated with the features of the framework itself. According to the famous "antenna effect" theory, we know that the emissions are attributed to energy transfer from the ligand to lanthanide ions. If guest molecules enter the framework, energy transfer may be perturbed, thereby, affecting the intensity of the luminescence [39-41]. In light of previous research [46-49], we assume the other possible reason of quenching is that the $\mathrm{Fe}^{3+}$ ions and acetone molecules may be adsorbed by the MOFs and may form interactions with the naked Lewis basic pyridyl active sites introduced by the ligand, ultimately resulting in a decrease in the efficiency of the transfer process from the ligand to the lanthanide centers.

In a word, multiple quenching mechanisms may co-work in the $\mathrm{Fe}^{3+}$ ions and acetone sensing process. Both competitive energy absorption and the influence of guest molecules on energy transfer may account for the quenching behavior of compounds toward $\mathrm{Fe}^{3+}$ ions and acetone.

\section{Materials and Methods}

\subsection{Chemicals and Reagents}

All chemicals and solvents including the $\mathrm{H}_{4} \mathrm{~L}$ ligand were purchased commercially and used without further purification.

\subsection{Apparatus}

Powder X-ray diffraction (PXRD) data were recorded using a Rigaku Miniflex 600 diffractometer (Rigaku, Tokyo, Japan). Infrared (IR) spectra using KBr slices were recorded using a PerkinElmer Spectrum One FT-IR (Fourier-transform infrared spectroscopy) spectrometer (PerkinElmer, Dublin, Ireland) ranging from 400 to $4000 \mathrm{~cm}^{-1}$. Element analyses (C, H, and N) were measured by a German Elemental Vario EL III instrument (Elementar Analysensysteme $\mathrm{GmbH}$, Langenselbold, Germany). Thermogravimetric analyses (TGA) were measured by a Netzsch STA 449c instrument (Netzsch Corporation, Selb, Germany)and were performed in the temperature range of ambient temperature to $900{ }^{\circ} \mathrm{C}$ with a heating rate of $10^{\circ} \mathrm{C} / \mathrm{min}$ under the flowing nitrogen environment. UV-vis study was recorded on a Lambda 365 (PerkinElmer, Waltham, MA, USA). The photoluminescence spectra of solid-state samples were collected by a Horiba Jobin-Yvon Fluorolog-3 fluorescence spectrometer (HORIBA Jobin Yvon, Kyoto, Japan). An Edinburgh Analytical Instruments FLS920 (Edinburgh Instruments, Edinburgh, UK) was used to capture the fluorescence lifetimes, and the overall photoluminescence quantum yields were investigated by using the integrating sphere covered with barium sulfate at room temperature.

\subsection{Synthesis of $\left\{\left[\mathrm{Me}_{2} \mathrm{NH}_{2}\right][\mathrm{LnL}] \cdot 2 \mathrm{H}_{2} \mathrm{O}\right\}_{n}(\mathrm{Ln}=\mathrm{Eu} \mathrm{1}, \mathrm{Tb}$ 2, Dy 3, Gd 4) (Compounds 1-4)}

In total, $45 \mathrm{mg}$ of $\mathrm{Ln}\left(\mathrm{NO}_{3}\right)_{3} \cdot 6 \mathrm{H}_{2} \mathrm{O}$ and $33 \mathrm{mg}$ of $\mathrm{H}_{4} \mathrm{~L}$ were dissolved in DMF $(N, N-$ dimethylformamide) $(5 \mathrm{~mL})$ and $\mathrm{H}_{2} \mathrm{O}(5 \mathrm{~mL})$. The solution was sealed in a $25-\mathrm{mL}$ Teflonlined stainless-steel autoclave, and heated at $160{ }^{\circ} \mathrm{C}$ for $72 \mathrm{~h}$. Then the mixture was cooled to room temperature at a rate of $1{ }^{\circ} \mathrm{C} / \mathrm{min}$. The resulting colorless crystals, $\left\{\left[\mathrm{Me}_{2} \mathrm{NH}_{2}\right][\mathrm{LnL}] \cdot 2 \mathrm{H}_{2} \mathrm{O}\right\}_{n}$, were washed with DMF and methanol several times, and then evacuated to remove the co-assembled DMF and methanol in the pores of MOFs. The yields are $68 \%, 72 \%, 76 \%$, and $75 \%$ for compounds 1-4 based on the metal ions. Elemental analysis (\%) calculated for the various crystals are listed as follows.

$\left\{\left[\mathrm{Me}_{2} \mathbf{N H}_{2}\right][\mathrm{EuL}] \cdot \mathbf{2} \mathbf{H}_{2} \mathrm{O}\right\}_{\mathbf{n}}$ (1) Elemental analysis (\%): calcd for $\mathrm{C}_{16} \mathrm{H}_{18} \mathrm{EuN}_{3} \mathrm{O}_{10}, \mathrm{C}$, 34.06; H, 3.22; N, 7.45. Found: C, 34.31; H, 3.12; N, 7.50. Infrared (KBr pellet, $\left.\mathrm{cm}^{-1}\right)$ : 3626(w), 3390(m), 3153(w), 3064(m), 2999(m), 2796(m), 2476(w), 1909(w), 1570(s), 1460(s), 1301(s), 850(s). 
$\left\{\left[\mathrm{Me}_{2} \mathbf{N H}_{2}\right][\mathrm{TbL}] \cdot 2 \mathrm{H}_{2} \mathrm{O}\right\}_{\mathbf{n}}$ (2) Elemental analysis (\%): calcd for $\mathrm{C}_{16} \mathrm{H}_{18} \mathrm{TbN}_{3} \mathrm{O}_{10}, \mathrm{C}$, 33.64; H, 3.18; N, 7.36. Found: C, 33.74; H, 3.09; N, 7.45. Infrared (KBr pellet, $\left.\mathrm{cm}^{-1}\right)$ : 3626(w), 3396(m), 3151(w), 3064(m), 2999(m), 2794(m), 2476(w), 1909(w), 1568(s), 1460(s), 1296(s), 850(s).

$\left\{\left[\mathrm{Me}_{2} \mathbf{N H}_{2}\right][\mathrm{DyL}] \cdot \mathbf{2} \mathrm{H}_{2} \mathrm{O}\right\}_{\mathrm{n}}$ (3) Elemental analysis (\%): calcd for $\mathrm{C}_{16} \mathrm{H}_{18} \mathrm{DyN}_{3} \mathrm{O}_{10}, \mathrm{C}$, 33.43; H, 3.16; N, 7.31. Found: C, 33.61; H, 3.04; N, 7.40. Infrared (KBr pellet, $\left.\mathrm{cm}^{-1}\right)$ : 3622(w), 3394(m), 3151(w), 3064(m), 2999(m), 2794(m), 2474(w), 1911(w), 1568(s), 1460(s), 1301(s), 850(s).

$\left\{\left[\mathrm{Me}_{2} \mathbf{N H}_{2}\right][\mathrm{GdL}] \cdot \mathbf{2} \mathrm{H}_{2} \mathrm{O}\right\}_{\mathbf{n}}$ (4) Elemental analysis (\%): calcd for $\mathrm{C}_{16} \mathrm{H}_{18} \mathrm{GdN}_{3} \mathrm{O}_{10}, \mathrm{C}$, 33.74; H, 3.19; N, 7.38. Found: $\mathrm{C}, 33.97 ; \mathrm{H}, 3.12 ; \mathrm{N}, 7.46$. Infrared (KBr pellet, $\left.\mathrm{cm}^{-1}\right)$ : 3626(w), 3398(m), 3149(w), 3064(m), 3000(m), 2792(m), 2476(w), 1909(w), 1568(s), 1460(s), 1305(s), 850(s).

\subsection{Single-Crystal X-ray Crystallography}

All the single-crystal $X$-ray diffraction data for the crystals were recorded on a supernova diffractometer with a multilayer mirror $\mathrm{Cu} K \alpha$ radiation $(\lambda=1.5418 \AA)$ or Mo $K \alpha$ $(\lambda=0.7107 \AA)$. All the structures of compounds $1-4$ were solved by a direct method of SHELX-97 and full-matrix least-squares refinement on $\mathrm{F}^{2}$ was performed using SHELX97 [50]. Except for some disordered water molecules, all non-hydrogen atoms were anisotropic refined on $\mathrm{F}^{2}$ by the full-matrix least-squares technique using the SHELXL-97. Only the $\left[\mathrm{Me}_{2} \mathrm{NH}_{2}\right]^{+}$counterion in $\mathrm{Gd}^{3+} \mathrm{MOF}$ can be solved from single crystal X-ray diffraction. The existences of $\left[\mathrm{Me}_{2} \mathrm{NH}_{2}\right]^{+}$in the other three MOFs and water molecules were further verified by the IR spectra, elemental analysis, and TGA data, obtaining the final chemical formulas of compounds 1-4. The CCDC (Cambridge Crystallographic Data Centre) numbers for compounds 1-4 are 2043852, 2043854, 2043855, and 2043853, respectively. See Tables S2-S5 for detailed crystallographic data.

\subsection{Sensing Experiment}

In metal ions sensing, $3 \mathrm{mg}$ of activated MOFs was ground to fine powder prepared for the experiments in aqueous solutions. The samples were then dispersed into $3 \mathrm{~mL}$ of various $\mathrm{M}\left(\mathrm{NO}_{3}\right)_{\mathrm{x}}$ aqueous solutions and ultrasonically dispersed to obtain uniform suspensions. Then the suspensions were loaded in the cuvettes for collecting the photoluminescence spectra. The fluorescence intensity of the suspension in water was measured as the blank sample.

In the $\mathrm{Tb}-\mathrm{MOF}$ paper sensor, uniformly dispersed suspension was obtained via an ultrasonic dispersal of Tb-MOF in di-chloromethane $\left(\mathrm{CH}_{2} \mathrm{Cl}_{2}\right)$, and then the suspension was evenly spread over the filter paper. After the dichloromethane volatilized and the filter paper dried, the Tb-MOF-coated paper sensor was obtained. The capillary dipped in $0.01 \mathrm{M} \mathrm{Fe}^{3+}$ ion aqueous solution was used to write "Fe" on the fluorescent test paper.

In organic solvents sensing, the experiments were carried out by dispersing $3 \mathrm{mg}$ of activated and ground MOFs into $3 \mathrm{~mL}$ of different organic solvents. After ultrasonic dispersing the sample evenly, the suspensions were added into the cuvettes and the photoluminescence tests were carried out. The fluorescence intensity of the suspension in DMF was measured as the blank sample.

In acetone vapor sensing, the ground Tb-MOF powder was tiled on the quartz slide to detect acetone vapor. The culture dish containing acetone was put into the inverted crystallizing dish to obtain saturated acetone vapor. After three hours, the quartz slide was put into the inverted crystallizing dish rapidly to make the sample power exposure to the saturated acetone vapor. After the reaction, the quartz slide was put into the fluorescence spectrometer for solid fluorescence detection.

\section{Conclusions}

In summary, a tetradentate carboxylic ligand with naked Lewis basic pyridyl active sites was employed to construct a series of lanthanide MOFs by the solvothermal method. 
The synthesized compounds have isomorphic structures with the topology point symbol of $\left\{4^{10} .6^{14} .8^{4}\right\}\left\{4^{5} .6\right\}_{2}$. Eu-, Tb-, and Dy-MOFs display red, green, and yellow emissions with the maximum peaks at 614,543 , and $574 \mathrm{~nm}$, respectively. The high quantum yields of Euand $\mathrm{Tb}-\mathrm{MOF}$ s suggest that $\mathrm{Eu}^{3+}$ and $\mathrm{Tb}^{3+}$ can be better sensitized by the ligand than $\mathrm{Dy}^{3+}$, which is also proven by their decay lifetimes. The material can detect $\mathrm{Fe}^{3+}$ in aqueous solution by a luminescence quenching effect with high selectivity, high sensitivity, and a rapid response $(<40 \mathrm{~s})$. The detection shows excellent anti-inference ability toward many other cations and can be easily recognized by naked eyes. The MOF can also sense acetone solvent and vapor selectively and rapidly. Thus, it may be a rapid luminescent probe for detecting $\mathrm{Fe}^{3+}$ and acetone, which can work at complicated circumstances. Furthermore, the framework shows not only good thermal stability but also excellent air and water stabilities, providing a basis for practical applications.

Supplementary Materials: The following are available online. Figure S1: IR spectra of compounds 1 (a), 2 (b), 3 (c), and 4 (d). Figure S2: The asymmetric unit of 4. Figure S3: The coordination mode of the $[\mathrm{L}]^{4-}$ ligand. Figure S4: PXRD patterns of compounds 1-4. Figure S5: TGA curves of compounds 1-4. Figure S6: (a) X-ray thermodiffractogram, (b) air stability, (c) water stability and (d) $\mathrm{pH}$ stability analyses of 2. Figure S7: (a) The excitation and emission spectra of ligand at room temperature. (b) The emission spectrum of 4 at $77 \mathrm{~K}$. Figure S8: Luminescence decay curves for 1 excited at $297 \mathrm{~nm}$ (a) and 2 excited at $299 \mathrm{~nm}$ (b) at $298 \mathrm{~K}$. Figure S9: Photoluminescence spectra of 2 in water and aqueous solutions containing different metal ions $\left(1 \times 10^{-3} \mathrm{M}\right)$ when excited at $299 \mathrm{~nm}$. Figure S10: Time-dependent photoluminescence spectra of 2 in $\mathrm{Fe}^{3+}$ aqueous solutions $\left(3 \times 10^{-4} \mathrm{M}\right)$. Figure S11: Photoluminescence spectra of 2 in pure water, aqueous solution of $\mathrm{Fe}^{3+}$ ion, other cations $\left(\mathrm{Li}^{+}, \mathrm{Ni}^{2+}, \mathrm{Mg}^{2+}, \mathrm{In}^{3+}, \mathrm{K}^{+}, \mathrm{Al}^{3+}, \mathrm{Zn}^{2+}, \mathrm{Ca}^{2+}, \mathrm{Cu}^{2+}\right)$ and all the cations, $1 \times 10^{-3}$ $\mathrm{M}$ each. Figure S12: Photoluminescence spectra of 2 in different organic solvents when excited at $299 \mathrm{~nm}$. Figure S13: Time-dependent photoluminescence spectra of $\mathbf{2}$ in the presence of acetone in DMF (0.1 vol.\%). Figure S14: PXRD patterns of 2 after dispersed in water and aqueous solutions containing different metal ions. Figure S15: PXRD patterns of $\mathbf{2}$ after immersed in acetone. Figure S16: UV-vis adsorption spectra of different metal ions in aqueous solution $\left(2 \times 10^{-4} \mathrm{M}\right)$. Figure S17: UV-vis adsorption spectrum of acetone in DMF (0.2 vol.\%). Figure S18: UV-vis adsorption spectra of $\mathrm{Fe}^{3+}$ aqueous solutions with different concentrations. Figure S19: (a) Photoluminescence spectra of 1 in water and aqueous solutions containing different metal ions $\left(1 \times 10^{-3} \mathrm{M}\right)$ when excited at $297 \mathrm{~nm}$. (b) Comparison of the ${ }^{5} \mathrm{D}_{0} \rightarrow{ }^{7} \mathrm{~F}_{2}$ photoluminescence intensity of $\mathbf{1}$ in water and aqueous solutions con-taining different metal ions when excited at $297 \mathrm{~nm}$. Figure S20: (a) Photoluminescence spectra of $\mathbf{1}$ in different organic solvents when excited at $297 \mathrm{~nm}$. (b) Comparison of the ${ }^{5} \mathrm{D}_{0} \rightarrow{ }^{7} \mathrm{~F}_{2}$ photoluminescence intensity of 1 in different organic solvents when excited at $297 \mathrm{~nm}$. Table S1: Room temperature quantum yields and lifetimes of compounds 1-3. Table S2: Selected bond lengths/ $\AA$ and bond angles $/{ }^{\circ}$ for compounds 1 . Table S3: Selected bond lengths $/ \AA$ and bond angles $/{ }^{\circ}$ for compounds 2. Table S4: Selected bond lengths $/ \AA$ and bond angles $/{ }^{\circ}$ for compounds 3. Table S5: Selected bond lengths $/ \AA$ and bond angles $/{ }^{\circ}$ for compounds 4 .

Author Contributions: Conceptualization, J.W. and L.C. Investigation, J.W. Methodology, M.Y. and S.L. Data analysis, J.W., L.C. and Z.L. Supervision, M.H. and L.C. Visualization, J.W., M.Y. and Z.L. Writing — original draft, J.W. Writing — review and editing, J.W., M.Y. and L.C. Project administration and funding acquisition, F.J. and M.H. All authors have read and agreed to the published version of the manuscript.

Funding: This research was funded by the National Key Research and Development Program of China (2018YFA0704502, 2019YFA0210402, 2017YFA0206800), "Strategic Priority Research Program" of the Chinese Academy of Sciences (XDB20000000), Key Research Program of Frontier Science CAS (QYZDY-SSW-SLH025), and the National Natural Science Foundation of China (21671189 and 21731006).

Informed Consent Statement: Not applicable.

Data Availability Statement: Not applicable. 
Acknowledgments: This work was financially supported by the National Key Research and Development Program of China (2018YFA0704502, 2019YFA0210402, 2017YFA0206800), “Strategic Priority Research Program" of the Chinese Academy of Sciences (XDB20000000), Key Research Program of Frontier Science CAS (QYZDY-SSW-SLH025), and the National Natural Science Foundation of China (21671189 and 21731006).

Conflicts of Interest: The authors declare no conflict of interest.

Sample Availability: Samples of the compounds are not available from the authors.

\section{References}

1. Yu, C.; Sun, X.; Zou, L.; Li, G.; Zhang, L.; Liu, Y. A pillar-layered Zn-LMOF with uncoordinated carboxylic acid sites: High performance for luminescence sensing $\mathrm{Fe}^{3+}$ and TNP. Inorg. Chem. 2019, 58, 4026-4032. [CrossRef]

2. Li, X.; Tang, J.; Liu, H.; Gao, K.; Meng, X.; Wu, J.; Hou, H. A highly sensitive and recyclable Ln-MOF Luminescent sensor for the efficient detection of $\mathrm{Fe}(3+)$ and $\mathrm{Cr}(\mathrm{VI})$ anions. Chem. Asian J. 2019, 14, 3721-3727. [CrossRef]

3. Yang, C.X.; Ren, H.B.; Yan, X.P. Fluorescent metal-organic framework MIL-53(Al) for highly selective and sensitive detection of $\mathrm{Fe}^{3+}$ in aqueous solution. Anal. Chem. 2013, 85, 7441-7446. [CrossRef]

4. Zhou, T.; Chen, S.; Wang, X.; Xie, C.; Zeng, D. Catalytic activation of cobalt doping sites in ZIF-71-coated ZnO nanorod arrays for enhancing gas-sensing performance to acetone. ACS Appl. Mater. Interfaces 2020, 12, 48948-48956. [CrossRef]

5. Ryu, U.; Jee, S.; Rao, P.C.; Shin, J.; Ko, C.; Yoon, M.; Park, K.S.; Choi, K.M. Recent advances in process engineering and upcoming applications of metal-organic frameworks. Coord. Chem. Rev. 2021, 426, 213544. [CrossRef]

6. Qin, G.; Wang, J.; Li, L.; Yuan, F.; Zha, Q.; Bai, W.; Ni, Y. Highly water-stable Cd-MOF/Tb ${ }^{3+}$ ultrathin fluorescence nanosheets for ultrasensitive and selective detection of Cefixime. Talanta 2021, 221, 121421. [CrossRef]

7. Batten, S.R.; Neville, S.M.; Turner, D.R. Coordination Polymers: Design, Analysis and Application; Royal Society of Chemistry: London, UK, 2009. [CrossRef]

8. MacGillivray, L.R.; Lukehart, C.M. Metal-Organic Framework Materials; MacGillivray, L.R., Lukehart, C.M., Eds.; John Wiley \& Sons: Chichester, UK, 2014. [CrossRef]

9. Zhang, J.; Biradar, A.V.; Pramanik, S.; Emge, T.J.; Asefa, T.; Li, J. A new layered metal-organic framework as a promising heterogeneous catalyst for olefin epoxidation reactions. Chem. Commun. 2012, 48, 6541-6543. [CrossRef]

10. Cha, G.Y.; Chun, H.; Hong, D.Y.; Kim, J.; Cho, K.H.; Lee, U.H.; Chang, J.S.; Ryu, S.G.; Lee, H.W.; Kim, S.J.; et al. Unique design of superior metal-organic framework for removal of toxic chemicals in humid environment via direct functionalization of the metal nodes. J. Hazard. Mater. 2020, 398, 122857. [CrossRef]

11. Ardila-Suárez, C.; Díaz-Lasprilla, A.M.; Díaz-Vaca, L.A.; Balbuena, P.B.; Baldovino-Medrano, V.G.; Ramírez-Caballero, G.E. Synthesis, characterization, and post-synthetic modification of a micro/mesoporous zirconium-tricarboxylate metal-organic framework: Towards the addition of acid active sites. CrystEngComm 2019, 21, 3014-3030. [CrossRef]

12. Lai, W.; Guo, J.; Zheng, N.; Nie, Y.; Ye, S.; Tang, D. Selective determination of 2,4,6-trinitrophenol by using a novel carbon nanoparticles as a fluorescent probe in real sample. Anal. Bioanal. Chem. 2020, 412, 3083-3090. [CrossRef] [PubMed]

13. Kim, K.J.; Culp, J.T.; Ohodnicki, P.R.; Cvetic, P.C.; Sanguinito, S.; Goodman, A.L.; Kwon, H.T. Alkylamine-integrated metal-organic framework-based waveguide sensors for efficient detection of carbon dioxide from humid gas streams. ACS Appl. Mater. Interfaces 2019, 11, 33489-33496. [CrossRef]

14. Liu, Q.; Tan, J.Y.; Zhang, J.Y.; Zhang, N.; Deng, W. R-Substituent induced structural diversity, synergistic effect and highly selective luminescence sensing for $\mathrm{Fe}^{3+}$ detection by post-synthetically modified Cd-MOFs. CrystEngComm 2020, 22, 3871-3883. [CrossRef]

15. Gogoi, C.; Reinsch, H.; Biswas, S. A pyrazine core-based luminescent $\mathrm{Zr}$ (iv) organic framework for specific sensing of Fe ${ }^{3+}$, picric acid and $\mathrm{Cr}_{2} \mathrm{O}_{7}^{2-}$. CrystEngComm 2019, 21, 6252-6260. [CrossRef]

16. Zhan, Z.Z.; Liang, X.Y.; Zhang, X.L.; Jia, Y.J.; Hu, M. A water-stable europium-MOF as a multifunctional luminescent sensor for some trivalent metal ions $\left(\mathrm{Fe}^{3+}, \mathrm{Cr}^{3+}, \mathrm{Al}^{3+}\right), \mathrm{PO}_{4}{ }^{3-}$ ions, and nitroaromatic explosives. Dalton Trans. 2019, 48, 1786-1794. [CrossRef] [PubMed]

17. Zhang, Q.S.; Jiang, X.; Kirillov, A.M.; Zhang, Y.; Hu, M.Y.; Liu, W.; Yang, L.Z.; Fang, R.; Liu, W.S. Covalent Construction of Sustainable Hybrid UiO-66- $\mathrm{NH}_{2} @$ Tb-CP Material for Selective Removal of Dyes and Detection of Metal Ions. ACS Sustain. Chem. Eng. 2019, 7, 3203-3212. [CrossRef]

18. Yang, L.Z.; Wang, J.; Kirillov, A.M.; Dou, W.; Xu, C.; Fang, R.; Xua, C.L.; Liu, W.S. 2D lanthanide MOFs driven by a rigid 3,5-bis(3-carboxy-phenyl)pyridine building block: Solvothermal syntheses, structural features, and photoluminescence and sensing properties. CrystEngComm 2016, 18, 6425-6436. [CrossRef]

19. Liu, Y.; Xie, X.Y.; Cheng, C.; Shao, Z.S.; Wang, H.S. Strategies to fabricate metal-organic framework (MOF)-based luminescent sensing platforms. J. Mater. Chem. C 2019, 7, 10743-10763. [CrossRef]

20. Jaros, S.W.; Sokolnicki, J.; Wołoszyn, A.; Haukka, M.; Kirillov, A.M.; Smoleński, P. A novel 2D coordination network built from hexacopper(i)-iodide clusters and cagelike aminophosphine blocks for reversible "turn-on" sensing of aniline. J. Mater. Chem. C 2018, 6, 1670-1678. [CrossRef] 
21. Li, Y.; Qin, C.; Li, Q.; Wang, P.; Miao, X.; Jin, H.; Ao, W.; Cao, L. Supramolecular organic frameworks with controllable shape and aggregation-induced emission for tunable luminescent materials through aqueous host-guest complexation. Adv. Opt. Mater. 2020, 8, 1902154. [CrossRef]

22. Masoomi, M.Y.; Morsali, A.; Dhakshinamoorthy, A.; Garcia, H. Mixed-metal MOFs: Unique opportunities in metal-organic framework (MOF) functionality and design. Angew. Chem. Int. Ed. Engl. 2019, 58, 15188-15205. [CrossRef] [PubMed]

23. Yang, Y.; Jiang, F.; Liu, C.; Chen, L.; Gai, Y.; Pang, J.; Su, K.; Wan, X.; Hong, M. Self-assembly syntheses, structural characterization, and luminescent properties of lanthanide coordination polymers constructed by three triazole-carboxylate ligands. Cryst. Growth Des. 2016, 16, 2266-2276. [CrossRef]

24. Gao, X.; Sun, G.; Ge, F.; Zheng, H. Three anionic indium-organic frameworks for highly efficient and selective dye adsorption, lanthanide adsorption, and luminescence regulation. Inorg. Chem. 2019, 58, 8396-8407. [CrossRef]

25. Peng, C.; Song, X.; Yin, J.; Zhang, G.; Fei, H. Intrinsic white-light-emitting metal-organic frameworks with structurally deformable secondary building units. Angew. Chem. Int. Ed. Engl. 2019, 58, 7818-7822. [CrossRef] [PubMed]

26. Meng, W.; Zeng, Y.; Liang, Z.; Guo, W.; Zhi, C.; Wu, Y.; Zhong, R.; Qu, C.; Zou, R. Tuning expanded pores in metal-organic frameworks for selective capture and catalytic conversion of carbon dioxide. ChemSusChem 2018, 11, 3751-3757. [CrossRef] [PubMed]

27. Liu, X.; Liu, J.; Sun, C.; Liu, H.; Wang, W.; Smith, E.; Jiang, L.; Chen, X.; Snape, C. Design and development of 3D hierarchical ultramicroporous $\mathrm{CO}_{2}$-sieving carbon architectures for potential flow-through $\mathrm{CO}_{2}$ capture at typical practical flue gas temperatures. J. Mater. Chem. A 2020, 8, 17025-17035. [CrossRef]

28. Aryanejad, S.; Motlagh, N.V. Investigation of the carbon dioxide adsorption behavior and the heterogeneous catalytic efficiency of a novel Ni-MOF with nitrogen-rich channels. RSC Adv. 2020, 10, 29772-29779. [CrossRef]

29. Singh, G.; Lee, J.; Karakoti, A.; Bahadur, R.; Yi, J.; Zhao, D.; AlBahily, K.; Vinu, A. Emerging trends in porous materials for $\mathrm{CO}_{2}$ capture and conversion. Chem. Soc. Rev. 2020, 49, 4360-4404. [CrossRef] [PubMed]

30. Wang, D.; Jana, D.; Zhao, Y. Metal-organic framework derived nanozymes in biomedicine. Acc. Chem. Res. 2020, 53, 1389-1400. [CrossRef]

31. Ma, D.D.; Zhu, Q.L. MOF-based atomically dispersed metal catalysts: Recent progress towards novel atomic configurations and electrocatalytic applications. Coord. Chem. Rev. 2020, 422, 213483. [CrossRef]

32. Chen, L.J.; Zhao, X.; Liu, Y.Y.; Yan, X.P. Macrophage membrane coated persistent luminescence nanoparticle@MOF-derived mesoporous carbon core-shell nanocomposites for autofluorescence-free imaging-guided chemotherapy. J. Mater. Chem. B 2020, 8 , 8071-8083. [CrossRef]

33. Ding, Y.; Xu, H.; Xu, C.; Tong, Z.; Zhang, S.; Bai, Y.; Chen, Y.; Xu, Q.; Zhou, L.; Ding, H.; et al. A nanomedicine fabricated from gold nanoparticles-decorated metal-organic framework for cascade chemo/chemodynamic cancer therapy. Adv. Sci. 2020, 7, 2001060. [CrossRef] [PubMed]

34. Liao, W.M.; Li, C.J.; Wu, X.; Zhang, J.H.; Wang, Z.; Wang, H.P.; Fan, Y.N.; Pan, M.; Su, C.Y. Homometallic Ln(iii)-complexes from an ILCT ligand with sensitized vis-NIR emission, excitation-dependent PL color tuning and white-light emission. J. Mater. Chem. C 2018, 6, 3254-3259. [CrossRef]

35. Guo, H.; Wu, N.; Xue, R.; Liu, H.; Wang, M.; Yao, W.; Wang, X.; Yang, W. An Eu(III)-functionalized Sr-based metal-organic framework for fluorometric determination of $\mathrm{Cr}(\mathrm{III})$ and $\mathrm{Cr}(\mathrm{VI})$ ions. Mikrochim. Acta 2020, 187, 374. [CrossRef] [PubMed]

36. Harbuzaru, B.V.; Corma, A.; Rey, F.; Atienzar, P.; Jordá, J.L.; García, H.; Ananias, D.; Carlos, L.D.; Rocha, J. Metal-organic nanoporous structures with anisotropic photoluminescence and magnetic properties and their use as sensors. Angew. Chem. Int. Ed. 2008, 47, 1080-1083. [CrossRef] [PubMed]

37. Wu, S.; Min, H.; Shi, W.; Cheng, P. Multicenter metal-organic framework-based ratiometric fluorescent sensors. Adv. Mater. 2020, 32, e1805871. [CrossRef] [PubMed]

38. Blatov, V.A.; Shevchenko, A.P.; Proserpio, D.M. Applied Topological Analysis of Crystal Structures with the Program Package ToposPro. Cryst. Growth Des. 2014, 14, 3576-3586. [CrossRef]

39. Wang, L.N.; Zhang, Y.H.; Jiang, S.; Liu, Z.Z. Three coordination polymers based on 3-( $3^{\prime}, 5^{\prime}$-dicarboxylphenoxy)phthalic acid and auxiliary N-donor ligands: Syntheses, structures, and highly selective sensing for nitro explosives and $\mathrm{Fe}^{3+}$ ions. CrystEngComm 2019, 21, 4557-4567. [CrossRef]

40. Duan, L.; Zhang, C.; Cen, P.; Jin, X.; Liang, C.; Yang, J.; Liu, X. Stable Ln-MOFs as multi-responsive photoluminescence sensors for the sensitive sensing of $\mathrm{Fe}^{3+}, \mathrm{Cr}_{2} \mathrm{O}_{7}{ }^{2-}$, and nitrofuran. CrystEngComm 2020, 22, 1695-1704. [CrossRef]

41. Hao, Z.; Yang, G.; Song, X.; Zhu, M.; Meng, X.; Zhao, S.; Song, S.; Zhang, H. A europium(iii) based metal-organic framework: Bifunctional properties related to sensing and electronic conductivity. J. Mater. Chem. A 2014, 2, 237-244. [CrossRef]

42. Nagarkar, S.S.; Desai, A.V.; Ghosh, S.K. A fluorescent metal-organic framework for highly selective detection of nitro explosives in the aqueous phase. Chem. Commun. 2014, 50, 8915-8918. [CrossRef]

43. Nagarkar, S.S.; Joarder, B.; Chaudhari, A.K.; Mukherjee, S.; Ghosh, S.K. Highly Selective Detection of Nitro Explosives by a Luminescent Metal-Organic Framework. Angew. Chem. Int. Ed. 2013, 52, 2881-2885. [CrossRef]

44. Wu, Z.F.; Fu, Z.H.; Velasco, E.; Xing, K.; Wang, H.; Zou, G.D.; Huang, X.Y.; Li, J. A robust and multifunctional calcium coordination polymer as a selective fluorescent sensor for acetone and iron (+3) and as a tunable proton conductor. J. Mater. Chem. C 2020, 8 , 16784-16789. [CrossRef] 
45. Yang, Y.; Chen, L.; Jiang, F.; Wu, M.; Pang, J.; Wan, X.; Hong, M. A water-stable 3D Eu-MOF based on a metallacyclodimeric secondary building unit for sensitive fluorescent detection of acetone molecules. CrystEngComm 2019, 21, 321-328. [CrossRef]

46. Tao, Y.; Zhang, P.; Liu, J.; Chen, X.; Guo, X.; Jin, H.; Chai, J.; Wang, L.; Fan, Y. Multi-responsive luminescent sensor based on three dimensional lanthanide metal-organic framework. New J. Chem. 2018, 42, 19485-19493. [CrossRef]

47. Liu, H.; Liu, Y.; Meng, Y.; Shi, X.; Sun, J.; Zhao, L.; Chen, D.; Hao, H.; Li, D.; Dou, J.; et al. Di-functional luminescent sensors based on $\mathrm{Y}^{3+}$ doped $\mathrm{Eu}^{3+}$ and $\mathrm{Tb}^{3+}$ coordination polymers: Fast response and visible detection of $\mathrm{Cr}^{3+}, \mathrm{Fe}^{3+}$ ions in aqueous solutions and acetone. RSC Adv. 2020, 10, 32232-32240. [CrossRef]

48. Gao, L.L.; Zhao, Q.N.; Li, M.M.; Fan, L.M.; Niu, X.Y.; Wang, X.Q.; Hu, T.P. Magnetic properties and luminescence sensing of five coordination polymers based on a rigid terphenyl-tetracarboxylic acid. CrystEngComm 2017, 19, 6651-6659. [CrossRef]

49. Xiao, Y.; Wang, L.; Cui, Y.; Chen, B.; Zapata, F.; Qian, G. Molecular sensing with lanthanide luminescence in a 3D porous metal-organic framework. J. Alloys Compd. 2009, 484, 601-604. [CrossRef]

50. Sheldrick, G. SHELXL-97, Program for Crystal Structure Refinement; University of Göttingen: Göttingen, Germany, 1997. 